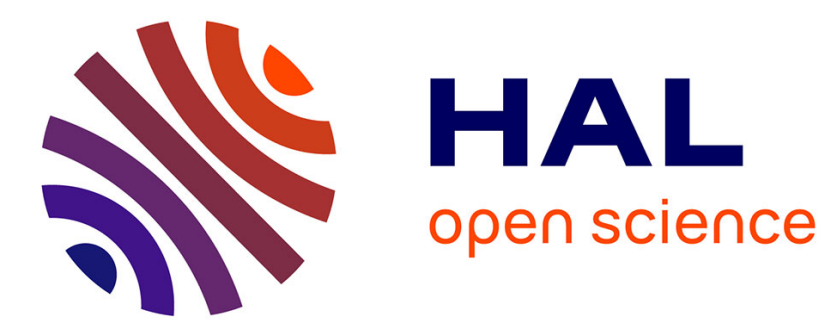

\title{
A Framework for Education 4.0 in Digital Education Ecosystems
}

Claudia-Melania Chituc

\section{To cite this version:}

Claudia-Melania Chituc. A Framework for Education 4.0 in Digital Education Ecosystems. 22nd Working Conference on Virtual Enterprises (PRO-VE 2021), Nov 2021, Saint-Etienne, France. pp.702709, 10.1007/978-3-030-85969-5_66. emse-03350033

\section{HAL Id: emse-03350033 https://hal-emse.ccsd.cnrs.fr/emse-03350033}

Submitted on 25 Nov 2021

HAL is a multi-disciplinary open access archive for the deposit and dissemination of scientific research documents, whether they are published or not. The documents may come from teaching and research institutions in France or abroad, or from public or private research centers.
L'archive ouverte pluridisciplinaire HAL, est destinée au dépôt et à la diffusion de documents scientifiques de niveau recherche, publiés ou non, émanant des établissements d'enseignement et de recherche français ou étrangers, des laboratoires publics ou privés. 


\title{
A Framework for Education 4.0 in Digital Education Ecosystems
}

\author{
Claudia-Melania Chituc \\ DIPF | Leibniz Institut for Research and Information in Education, Rostocker Straße 6, \\ 60323 Frankfurt am Main, Germany \\ Chituc@dipf.de
}

\begin{abstract}
The digital technologies enable the transformation of the educational institutions, shaping the way teaching and learning knowledge and skills activities are delivered and assessed, and the pursuance of the Digital Education Ecosystems (DEEs). Industry 4.0 requires highly qualified employees, and the concept of Education 4.0 emerged, which focusses on preparing the future workforce for Industry 4.0. Despite the importance of Education 4.0, research and development work in this area is in an incipient phase, and the fields of Education 4.0 and DEEs expand without a clear vision how the necessities of Industry 4.0 will be addressed, and how the DEEs support attaining the goals of Education 4.0. The aim of this article is to present a framework for Education 4.0 developed by performing a literature review, which contains six dimensions: knowledge, skills and qualifications in Education 4.0; teaching; learning; implementation; (e-)assessment; and quality assurance.
\end{abstract}

Keywords: Education 4.0, digital technologies, Industry 4.0, digital education ecosystem.

\section{Introduction}

The digitalization of the education sector is accelerated by the recent advances in the digital tools and technologies, such as: big data analytics, cloud computing, machine learning, Internet of Things (IoT), sensing and actuation technologies, 3D printing, social media. They enable the transformation of the educational institutions, shaping (next to disruptions caused by epidemic occurrences) the educational activities and services, the way teaching and learning knowledge and skills activities are delivered and assessed, and the pursuance of the Digital Education Ecosystems (DEEs). While the concept of DEE is not new in the fields of engineering or social sciences (see: [1][2]), the interest in digitally enhanced teaching and learning activities is expanding in recent times as numerous benefits are acknowledged.

The DEEs refer in this work to inter-connected heterogeneous and geographically distributed e-learning infrastructure, software tools and devices used in education activities. The IoT and Cyber-Physical Systems (CPSs) (which are pillars of Industry 4.0) enable the realization of the DEEs. 
The Industry 4.0 concept, as noted in [3], emerged from the industrial revolution in Germany, with a solid background (scientific, technical, industrial) constructed on the melding of industrial norms and standards based on a novel DIN (Deutsche Industrie Norm) specification: the Reference Architecture Model (RAMI4.0) [4]. Industry 4.0 requires highly qualified employees [5]. The Education 4.0 concept emerged, which focuses on preparing the future workforce for Industry 4.0.

Despite the importance of Education 4.0, this is a recent field, and research and development work in this area is in an incipient phase [6]. Moreover, the fields of Education 4.0 and DEEs expand without a clear vision how the necessities of Industry 4.0 will be addressed, and how the DEEs support attaining the goals of Education 4.0. Relevant research questions in this area that need to be addressed are: Which are the key dimensions to characterize Education 4.0? How Education 4.0 is currently tackled? Which are enablers for Education 4.0 in the DEEs? Which are challenges for Education 4.0 that need to be further addressed?

Aiming to answer these research questions, this article presents a framework for Education 4.0 in the inter-connected DEEs. The notion of framework is understood here as a structure underlying the concept of Education 4.0. The findings of a literature review performed following PRISMA guidelines [7] represent the basis of the proposed framework, which is structured in six dimensions: knowledge, skills and qualifications; teaching; learning; implementation; (e-)assessment; and quality assurance. This framework reflects the main dimensions and characteristics of Education 4.0, and is useful for educators and educational institutions, enterprises, policy makers in better understanding the emerging fields of Education 4.0, and identifying areas that need to be further addressed by research and development work.

This article is organized as follows. Background information is introduced next. The research approach and related work are presented in Section 3. A framework for Education 4.0 is described in Section 4. This articles concludes with a section addressing the need for future research and development work.

\section{Background: The Role of DEEs in Education 4.0}

While in the traditional e-learning environments the students and educators connect to an e-learning platform (such as Moodle, moodle.org) to perform basic activities (e.g., execute quizzes, access e-learning material), the DEEs enable the rendering of convoluted e-learning activities (e.g., to support the execution of remote complex group work activities using virtual reality, 3D printing, interactive whiteboards, cloud computing) and real-time analysis of huge volumes of heterogeneous data (e.g., to allow the human or robot teacher to adjust or individualize the teaching activities).

Numerous benefits are associated with the DEEs enabled by the IoT technologies and CPSs, such as: enrich learners' psychological experiences in learning activities, allowing interaction, collaboration and flexibility [8], enhanced learning [9], and help organizations to improve the quality of teaching and learning by allowing a richer learning experience and real-time analysis of learners' performance [10].

Several e-learning management systems exist (e.g., Moodle, Canvas instructure.com/canvas, Blackboard blackboard.com, Army Learning Management 
System-ALMS atris.mil/ALMS) and standardization initiatives to address interoperability among e-learning infrastructures, such as: Learning Object Metadata promoted by the IEEE Learning Technology Standards Committee (ltsc.ieee.org), which advocates for storing learning objects as well as their descriptions; IMS Question and Test Interoperability (www.imsglobal.org), which specifies an XML format for encoding on-line questions, tests and test banks. As the field of e-learning is expanding without a clear vision on how heterogeneous software systems, "things" and e-learning infrastructures should inter-relate, the attainment of interoperable $\mathrm{DEEs}^{1}$ is still not achieved, which brings numerous challenges for Education 4.0.

It is important to ensure collaboration and transfer of technology and technology knowledge among the main DEE stakeholders (e.g., students, educators, educational institutions, companies, research centers, government structures) towards ensuring the highly qualified workforce needed in Industry 4.0 (see: [11]). Thus, the DEEs enable Education 4.0, and attaining interoperability in DEEs is crucial for Education 4.0.

\section{Research Approach and Discussion of Related Work}

Aiming to identify the main dimensions to characterize Education 4.0, relevant approaches and challenges, a literature review was conducted following PRISMA guidelines [7]. The digital libraries of IEEE, ACM, Elsevier and Springer were searched as they represent the most important databases in the area of Education 4.0 and Industry 4.0. Queries on Google Scholar were also performed. Keywords identified include: "Education 4.0", "characteristic", "challenge", "Industry 4.0", "work force", "qualification", "skills" "classroom 4.0", "study program", "digital skills", "teaching", "digital learning", "learning factory", "future manufacturing". Queries executed included the Boolean operators OR, AND, NOT, e.g., ("Education 4.0" AND “challenge"); (("Industry 4.0" OR "future manufacturing”) AND “work force" AND ("qualification" OR "skills" OR "digital skills")). The search concerned articles published from January 2015 to April 2021. As the list of retrieved articles was vast, inclusion and exclusion criteria were defined. For example, by reading the title and abstract, the clearly out of scope articles were excluded. The articles written in a language other than English and articles to which full access was not possible were also excluded. The relevant articles were read in full, and an analysis of related work was made.

Industry 4.0 determines a shift in the required skills and qualifications of the workforce [12][13]. The technical and personal skills and qualifications required for Industry 4.0 are analyzed in [14], grouped in "must have", "should have" and "could have". Accordingly, "must have" technical skills include IT knowledge and abilities, data and information processing and analytics, statistical knowledge, organizational and processual understanding, ability to interact with modern interfaces (humanmachine/ human-robot), "must have" personal skills concern self- and time

${ }^{1}$ Interoperability in the context of DEEs refers here to the ability of inter-connected e-learning ICT infrastructures, software systems and "things" to exchange information and interpret it in the same way. 
management, adaptability, ability to change, team work abilities, social and communication skills, "should have" technical skills include knowledge management, interdisciplinary/ generic knowledge about technologies and organizations, specialized knowledge of manufacturing activities and processes, awareness of IT security and data protection, and "should have" personal skills include trust in new technologies and mindset for life-long learning [14].

Examining the inter-disciplinary field of Industry 4.0, on one hand, and the traditional engineering study programs, it is very challenging for educators and students (or recent graduates) to meet these demands, e.g., concerning learning, teaching, understanding the informatization, digitalization and networking of the industrial and business ecosystem [3]. Classic lecture-based teaching seems not adequate [15]. Education 4.0 emerged to address these demands and challenges. Although the field of Education 4.0 is in an incipient phase [6], some studies exist that illustrate the implementation of Education 4.0 pilots at educational institutions. The use and importance of "demonstration platforms" for the design, implementation, test, optimization of Industry 4.0-complian solutions by teachers, students in university in a multi-disciplinary fashion is emphasized in [3], where the authors present the "Automated Class Room" demonstrator platform at the University of Applied Sciences in Emden. Upgrades of learning factories (e.g., implementation of CPSs in learning factories, smart factories in Industry 4.0) are referred in the literature as approaches towards preparing highly skilled workforce required in Industry 4.0, e.g.,[16][17][18]. The inclusion of mandatory subjects relevant for Industry 4.0 in education curricula, internships, MOOCs, open day tours, workshops, professional development courses, industry-university collaborations are noted in [14] as approaches to address the "must have" and "should have" skills and qualifications for Industry 4.0. Learning approaches in Education 4.0 noted in [19] include, among others, blended, personalized and experimental learning, and mentoring through peers. The authors also refer to the need for customized learner's evaluation. Gamification is also used in Education 4.0 [20]. The need for adaptive learning powered by artificial intelligence learning portals that allow to adapt the learning process considering the learner's profile is emphasized in [21].

Five clusters of scientific gaps for Education 4.0 are discussed in [6]: to map and assess Education 4.0 challenges and solutions to Industry 4.0, pedagogical alignment, analyze novel teaching methods in Education 4.0, optimize and update Education 4.0 digital platforms. Next to education institutions and companies, the importance of policymakers in Education 4.0 in noted in [22][19], e.g., for accreditation, global outlook, support in collaborations, implement the Education 4.0 vision.

The finding of the related work represent the basis for the development of the Education 4.0 framework described next.

\section{Framework for Education 4.0}

Fig. 1 illustrates the proposed framework for Education 4.0. This framework was constructed considering the main characteristics and challenges of Education 4.0 identified from the literature review conducted, which were grouped in six 
dimensions: (1) knowledge, skills and qualifications required by Industry 4.0 that need to be addressed in Education 4.0, (2) teaching approaches, concerning methods for teaching technical and personal skills, and pedagogy approaches, (3) learning approaches, (4) implementation of the Education 4.0 vision, teaching methods, and ensuring an environment where innovation, knowledge and technology transfer are promoted, (5) (e-)assessment, which concerns the methods and (technology-based) assessment methods, tools and infrastructures used to evaluate the knowledge and skills, tailored considering the specificities of Education 4.0 and specific teaching and learning methods, (6) quality assurance, concerning the methodologies, methods, metrics and tools for evaluating the quality of the teaching, and regulate diploma issuing, accreditation and verification processes. Figure 1 also illustrates examples of approaches used (or which could be relevant) in each dimension. These aspects are also relevant in the construction of the DEEs.

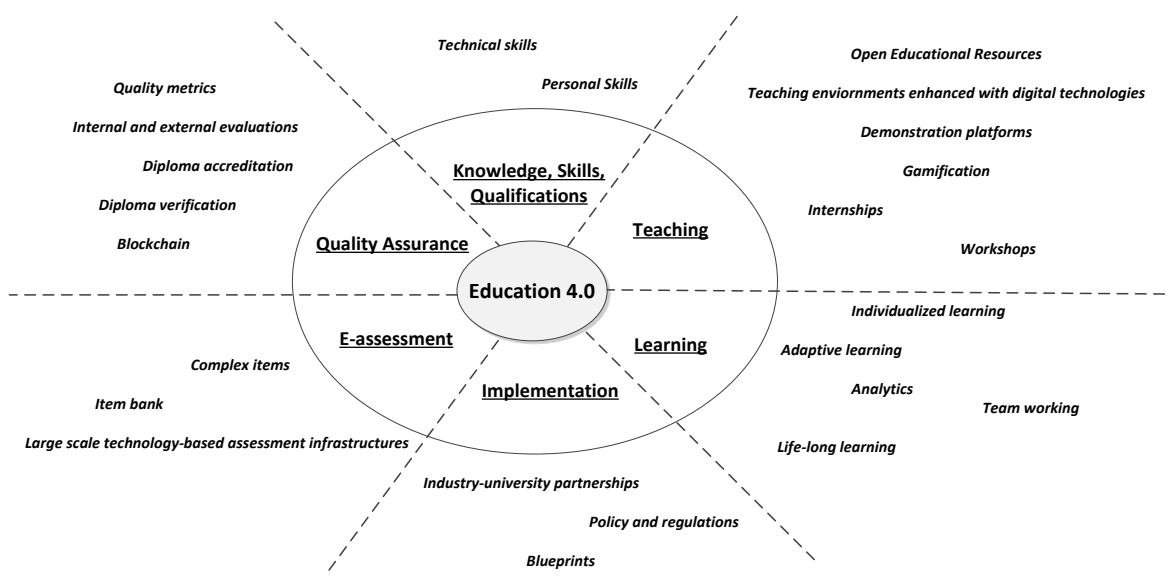

Fig. 1. Framework for Education 4.0

Although Education 4.0 is a recent domain, several studies exist in the context of Education 4.0 focusing on the knowledge, skills and qualifications required for Education 4.0 (see:[14][3]), teaching (see: [20][3]) and learning (see: [21][19]) approaches. Several requirements for universities also need to be addressed, such as: advanced infrastructures, skilled staff, increased industrial partnership, revised curricula, effective financial planning [23].

Few studies focus on the actual implementation of Education 4.0 approaches, although the importance of policymakers in this process is acknowledged (e.g. [19][22]), and on e-assessment approaches. Adequate complex items, item banks, and large scale ICT infrastructures for technology-based assessments are needed. Research in this area has intensified in the past years (e.g., approaches for the development of item banks for complex items are described in: [24][25]). However, ensuring a kind of "widely-accepted" e-assessment approach (relevant in the context of globalization, students' participation in international educational activities and exchange programs, and life-long learning programs) is very challenging, e.g., this requires the translation of complex items - often accompanied by audio or video files 
- in different languages, which may change the level of difficulty of the respective item. Technology-based assessments are focusing in recent years on large-scale adaptive testing and multi-testing applications, which require advanced support for item design and editing, assessment assignments, and access to additional test materials. Solutions that reflect the content, interaction patterns, psychometric item and test analysis, quality control software, test delivery software and hardware are needed [26]. However, Education 4.0 does not exclude the use of traditional assessment methods.

Ensuring quality assurance in Education 4.0 is not tackled currently, and this is a crucial topic especially considering the specificities of Education 4.0, mobility in education, and the increasing competition faced nowadays by educational institutions (that are traditionally acknowledged as main providers of educational activities) as more and more companies develop and offer teaching programs. Quality assurance in education is not a new topic (see: [27][28]). Several quality assurance systems were developed along the years, e.g., by the Educational Testing Service [29], Association for Educational Assessment Europe [30], Cambridge Assessment [31]. However, the primary focus of most such systems, standards, guidelines, or formal reviewing systems is on psychological testing, and they are not fully suitable to assess the quality of educational tests or exams [32], and often they do not address the specificities of technology-based assessments that rely on the concepts of item and item bank. Research and development work needs to address these aspects in the context of Education 4.0. The development of quality assurance metrics, methods, methodologies and software tools for Education 4.0 can build on previous approaches. However, aspects such as ethics and fairness in artificial intelligence-enabled eassessment approaches need to be carefully tackled, and the policymakers can have an important role in the development of adequate e-assessment and quality assurance methods and methodologies in Education 4.0.

\section{Conclusions and Future Work}

Education 4.0 brings numerous challenging for educational institutions in developing and implementing teaching and learning approaches needed to ensure the technical qualifications and personal skills of young graduates required by Industry 4.0. The DEEs, enhanced with digital technologies, support teaching and learning activities, and the establishment of partnerships or networks among educational institutions and enterprises to tackle these challenges.

The findings of a literature review performed following PRISMA guidelines [7] represent the basis of an Education 4.0 framework (Fig. 1) structured in six dimensions: knowledge, skills and qualifications for Education 4.0; teaching; learning; implementation; (e-)assessment; and quality assurance. While studies exit on identifying the required knowledge and skills, teaching, learning approaches in the context of Industry 4.0, few works focus on e-assessment and quality assurance. Future research and development work in Education 4.0 should focus on these topics. Aspects such as ethics and fairness in artificial intelligence-enabled e-assessment approaches also need to be addressed. The policymakers can have an important role in 
the development of adequate assessment and quality assurance approaches in Education 4.0, and in defining blueprints for their implementation.

Another important aspects to be tackled is pedagogical knowledge in the context of Education 4.0. Digital technologies enable Education 4.0. However, existing approaches lack pedagogical knowledge and strategy. The educators and educational institutions need to select and implement appropriate techniques to optimally combine adequate educational resources, technology and a pedagogy strategy to address the workforce needs of Industry 4.0. Future research and development work will focus on developing a methodology to support educators in making appropriate decision about e-learning optimally combining these aspects.

\section{References}

1. Ficheman I.K., Lopes R. de D.: Digital learning ecosystems: authoring, collaboration, immersion and mobility. ACM IDC, 9--12 (2008)

2. Mavrikis M., Guardia L., Cukurova M., Maina M.: A Digital Ecosystem for Digital Competences: The CRISS Project Demo. In: Pammer-Schindler V. et al. (eds.) Lifelong Technology-Enhanced Learning. EC-TEL. LNCS 11082. Springer, Cham, 627--630 (2018)

3. Wermann J., Colombo A.W., Pechmann A. et al.: Using an interdisciplinary demonstration platform for teaching Industry 4.0, Procedia Manufacturing 31, 302--308 (2019)

4. DIN Deutsches Institut für Normung e.V.: DIN SPEC 91345:2016-04: Referenzarchitekturmodell Industrie 4.0 (RAMI4.0) (2016)

5. Benesova A., Tupa J.: Requirements for education and qualification of people in Industry 4.0. Procedia Manufacturing 11, 2195--2202 (2017)

6. da Motta Reis et al.: Education 4.0: Gaps research between school formation and technological development. In: Latifi S. (eds.) $17^{\text {th }}$ International Conference on Information Technology - New Generation ITNG 2020. Advances in Intelligent Systems and Computing vol. 1134, Springer, Cham, 415--420 (2020)

7. Moher D. et al.: Preferred reporting items for systematic review and meta-analyses: The PRISMA statement. PLOS Medicine 6(7), e1000097 (2009)

8. Chang F.-C. et al.: Future classroom with the Internet of Things - A service-oriented framework, Journal of Information Hiding and Multimedia Signal Processing 6(5), 869--881 (2015)

9. Bagheri M., Siavosh, H.M.: The Effect of the Internet of Things (IoT) on Education Business Model, IEEE SITIS, 435--441 (2016)

10. Boyes H., Hallaq B. et al.: The industrial Internet of Things (IIoT): An analysis framework, Computers in Industry vol. 101, 1--12 (2018)

11. Tirto T., Ossik Y., Omelyanenko V.: ICT Support for Industry 4.0 Innovation Networks: Education and Technology Transfer Issues. In: Ivanov V. et al. (eds.) Advances in Design, Simulation and Manufacturing II. DSMIE 2019. Lecture Notes in Mechanical Engineering. Springer, Cham., 359--369, (2020)

12. Siemens AG: Competences for the future of manufacturing, Siemens Industry Journal 2 , $11--25(2013)$

13. Hammer M., Hippe M., Schmitz C., Sellschop R., Somers K.: The dirty little secret, Harvard Business Review (2016). Accessed on 30.04.2021 at: https://hbr.org/2016/05/thedirty-little-secret-about-digitally-transforming-operations

14. Gehrke L., Kühn A., Rule D., Moore P., Bellmann C. et al.: A Discussion of Qualifications and Skills in the Factory of the Future: A German and American Perspective, VDI The Association of German Engineers, Düsseldorf, Germany (2015) 
15. Karre H., Hammer M., Kleindienst M. et al.: Transition towards an Industry 4.0 state of the LeanLab at Graz University of Technology, Procedia Manufacturing 9, 206--213 (2017)

16. Thiede S., Juraschek M., Christoph H.: Implementing cyber-physical production systems in learning factories. Procedia CIPR 54, 7--12 (2016)

17. Prinz C., Morlock S., Freith et al.: Learning factories modules for smart factories in Industry 4.0. Procedia CIRP 54 113--118 (2016)

18. Centea D., Singh I.,Wanyama T., Magolon M., Boer J., Elbestawi M. Unsing SEPT learning factory for the implementation of Industry 4.0: case of SMEs. Procedia Manufacturing 45, 102--107 (2020)

19. Koul S., Nayar B.: The holistic learning educational ecosystem: A classroom 4.0 perspective, Higher Education Quarterly 75, 98--112 (2021)

20. Almeida F., Simoes J.: The role of serious games, gamification and Industry 4.0 tools in the Education 4.0 paradigm, Contemporary Educational Technology 10(2), 120--136 (2019)

21. Demartini B., Benussi L.: Do Web 4.0 and Industry 4.0 imply Education X.0? IT Pro, May/June, IEEE, 4--7 (2017)

22. Halili S.H., Technological advancements in Education 4.0, The Online Journal of Distance Education and e-Learning 1(7), 63-69 (2019)

23. Mian S.H., Salah B., Ameen W. et al.: Adapting universities for sustainability education in Industry 4.0: challenges and opportunities, Sustainability, 12, 6100 (2020)

24. Petersen, M.A., et al.: Development of an item bank for computerized adaptive test (CAT) measurement of pain. Qual. Life Res. 25(1), 1-11 (2016)

25. Chituc C.-M., Herrmann M., Schiffner D., Rittberger M.: Towards the Design and Deployment of an Item Bank: An Analysis of the Requirements Elicited. In: Herzog M. et al. (eds) Advances in Web-Based Learning - ICWL 2019. ICWL 2019. Lecture Notes in Computer Science, vol 11841. Springer, Cham, 155--162 (2019)

26. Luecht, R.M.: Computer-based test delivery models, data, and operational implementation issues, In: F. Drasgow (ed.), Technology and testing: Improving educational and psychological measurement, New York: Routledge, 179--205 (2016)

27. Buros, O.K. (Ed.) The 1938 mental measurements yearbook. Oxford, England: Rutgers University Press (1938).

28. Bartram, D.: Review model for the description and evaluation of psychological tests. Brussels, Belgium: European Federation of Psychologists' Associations (2002)

29. Educational Testing Service: ETS standards for quality and fairness. Princeton: Educational Testing Service (2014)

30. Association of Educational Assessment-Europe: European framework of standards for educational assessment 1.0. Roma: Edizione Nova Cultura (2012). Retrieved from: www.aeaeurope.net/wpcontent/uploads/2017/07/SW_Framework_of_European_Standards.pdf

31. Cambridge Assessment: Cambridge Approach to Assessment (2017). Retrieved from: www.cambridgeassessment.org.uk/Images/cambridge-approach-to-assessment.pdf

32. Hemker, B., Sluijter, C., Sanders, P.: Assessing Computer-Based Assessments. In: Veldkamp B., Sluijter C. (eds) Theoretical and Practical Advances in Computer-based Educational Measurement. Methodology of Educational Measurement and Assessment. Springer, Cham, 73-89 (2019) 